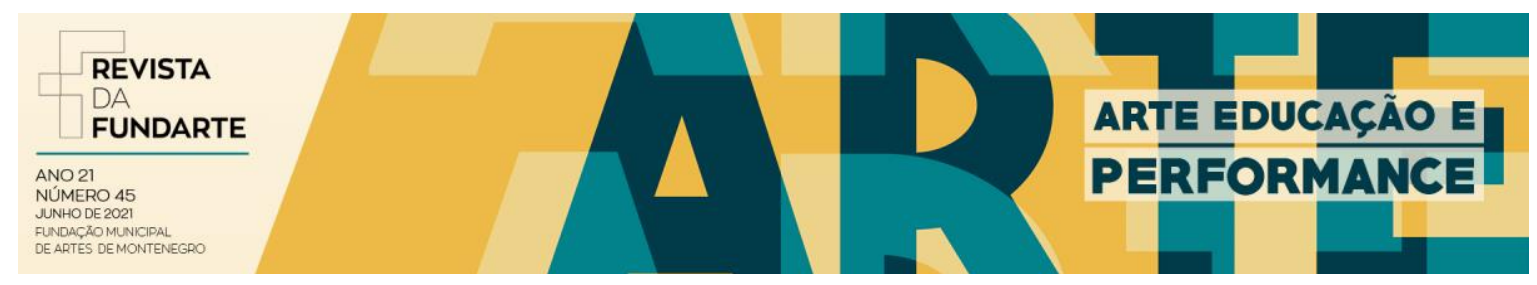

\title{
A EDUCAÇÃO NÃO FORMAL NAS LICENCIATURAS EM ARTES VISUAIS DA PERSPECTIVA DAS POLÍTICAS EDUCACIONAIS
}

Cayo Honorato

DOI: $10.19179 / 2319-0868 / 833$ 


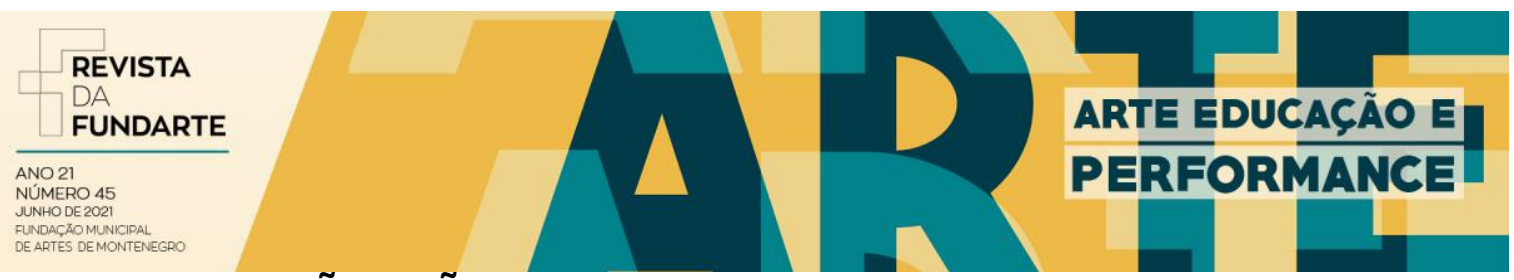 \\ A EDUCAÇÃO NÃO FORMAL NAS LICENCIATURAS EM ARTES VISUAIS DA PERSPECTIVA DAS POLÍTICAS EDUCACIONAIS
}

Cayo Honorato ${ }^{1}$

Resumo: Considerando a publicação da Resolução CNE/CP no 2, de 20 de dezembro de 2019, que trata da BNC-Formação, este artigo retoma o problema do lugar da educação não formal na formação assegurada pelos cursos de Licenciatura em Artes Visuais. Duas problemáticas organizam a sua discussão: (1) a relação entre teoria e prática e (2) a vinculação dos estágios à escola. Assumindo que a possibilidade do estágio na educação não formal é limitada por essa Resolução, o artigo decide por evidenciar suas incongruências, para além de criticar suas formulações. Em suma, se participar das manifestações culturais é uma das competências que o professor deve desenvolver, por que ele não poderia atuar nos espaços que são próprios a essas manifestações?

Palavras-chave: Educação não formal; Educação em museus; Mediação cultural.

\section{INFORMAL EDUCATION IN TEACHER TRAINING COURSES IN VISUAL ARTS FROM THE PERSPECTIVE OF EDUCATIONAL POLICIES}

\begin{abstract}
Considering the publication by the Brazilian Ministry of Education in December, 2020, of a resolution that regulates teacher training courses at higher education, this article takes up the problem of which place informal education has in those courses, particularly in the field of visual arts. Two issues organize its discussion: (1) the relationship between theory and practice and (2) the schools as an exclusive site for supervised practice. Assuming the possibility that such practice in informal education is limited by that resolution, the article decides to highlight its inconsistencies, in addition to criticizing its formulations. In short, if taking part in cultural life is one of the skills that the teachers must develop, why they could not work in spaces specifically related to cultural expressions?
\end{abstract}

Keywords: Informal education; Museum education; Gallery education.

Preocupado com a caracterização de cada uma destas modalidades, o debate sobre as diferenças entre a educação formal e a não formal por vezes ignora o problema da formação universitária para a educação não formal (GOHN, 2010, 2015; MARANDINO, 2017; JACOBI, 2018). Certamente, aquele debate deve continuar, já que os termos "formal”, "não formal", "informal" etc. têm sido usados de maneira controversa e suas definições não são consensuais (MARANDINO, 2017). Mas o problema da formação para o "não formal" excede a discussão conceitual, envolvendo questões políticas e econômicas, relativas ao reconhecimento da educação

\footnotetext{
1 Professor Adjunto no Departamento de Artes Visuais (VIS) do Instituto de Artes (IdA) da Universidade de Brasília (UnB), na área de História e Teoria da Educação em Artes Visuais.
}

HONORATO, Cayo. A educação não formal nas licenciaturas em artes visuais da perspectiva das políticas educacionais. Revista da FUNDARTE. Montenegro, p.01-19, ano 21, no 45, junho de 2021. Disponível em: http://.seer.fundarte.rs.gov.br/index.php/revistadafundarte/index> 30 de junho de 2021. 


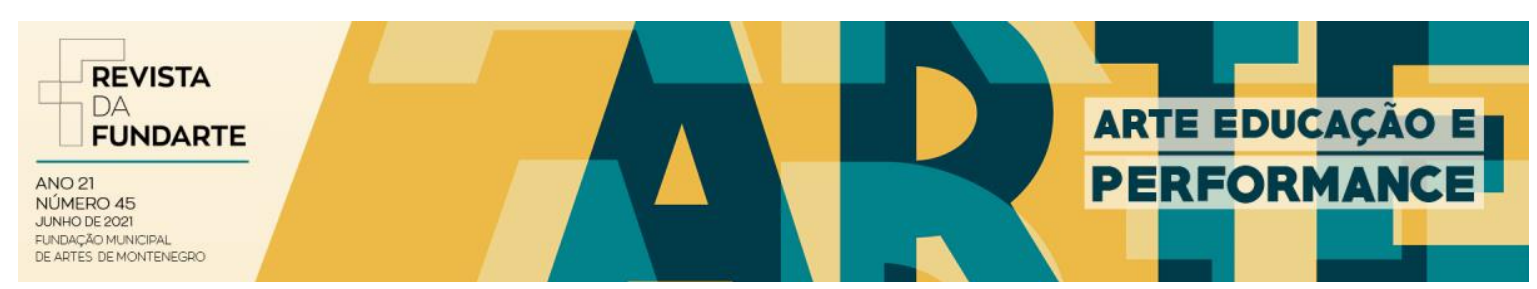

não formal pelos marcos legais que dizem respeito ao ensino superior e à formação de professores.

Podemos situar esse problema no âmbito das colaborações entre o formal e o não formal, com a ressalva de que ele escapa àquilo que Anik Meunier (2018, p. 18, tradução minha) chamou de "educação formal deslocada", referindo-se a quando a escola vai ao museu ou usa ferramentas desenvolvidas pela educação museal. Trata-se aqui de pensarmos as condições para uma colaboração mais sistemática, dentre as quais está o reconhecimento por parte dos currículos universitários de outras concepções de educação - sejam aquelas associadas ao conceito de cultura (BRANDÃO, 2002; GOHN, 2010) ou à ideia de free-choice learning (FALK; DIERKING, 2002) - enquanto campos de pesquisa e atuação igualmente legítimos. Neste artigo, refiro-me particularmente (1) à educação em museus ou à mediação cultural como formas de educação não formal e (2) à licenciatura em artes visuais como opção de formação universitária.

Dentre as pesquisas já realizadas sobre a interseção dessas duas instâncias, algumas se perguntaram como formar o mediador cultural a partir de uma determinada disciplina (MOURA, 2007), enquanto outras se dedicaram a traçar o perfil desses profissionais, considerando dados relativos à sua formação (ALENCAR, 2008). Nenhuma delas abordou a colaboração entre aquelas instâncias (museu e universidade), enquanto ambientes institucionais distintos. Essa colaboração também não é abordada pelas pesquisas sobre a formação dos mediadores assumida pelos museus, eventualmente chamada de "formação em serviço" (BARBOSA; COUTINHO, 2009 , p. 9). Mais próximas daquela interseção, há pesquisas que discutiram a atuação das Práticas de Ensino em relação a múltiplos espaços educacionais, considerando o estágio supervisionado em museus como um mediador fundamental desse processo (MAGALHÃES, 2002, p. 161-74). Minha hipótese é que essa compreensão não goza de pleno reconhecimento legal. Daí perguntar: qual o espaço reservado à formação de mediadores na universidade, do ponto de vista das políticas educacionais?

Parte das respostas a esse problema foi dada por Guilherme Nakashato (2009, p. 20 e 43), que se propôs a "debater o papel do estágio curricular supervisi- 


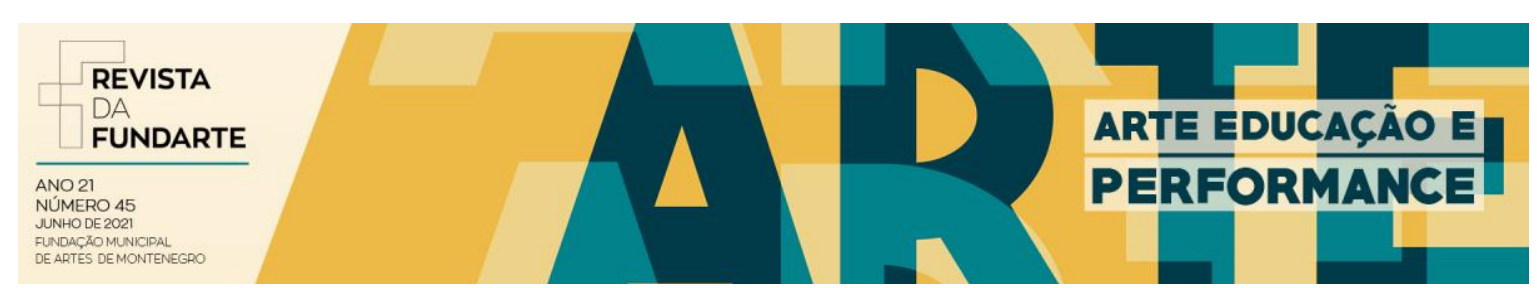

onado [em educação não formal] na formação inicial do professor", ao mesmo tempo em que perguntava se "os cursos de graduação em artes visuais deveriam incluir a educação não-formal como parte de suas exigências curriculares". Referindo-se a uma de suas experiências como professor em uma faculdade privada, Nakashato relata sua insatisfação diante da "sugestão", ratificada pelo setor jurídico da instituição, de que os estágios na educação não formal não seriam computados como parte da carga horária obrigatória do curso. O pesquisador entendeu que "as normas que direcionam os cursos de graduação são taxativas no sentido em que as vivências buscadas [no estágio] são orientadas para a educação formal”. Apesar disso, concluiu pela "competência das universidades em elaborar seus próprios planos de estágio supervisionado", alertando para a situação das Instituições de Ensino Superior (IES) que não têm a mesma autonomia das universidades (NAKASHATO, 2009, p. 61-2). Essa situação contraditória persiste até hoje. Mas se o direcionamento geral daquelas normas praticamente não mudou, talvez seja a sua própria persistência o que agora podemos examinar, com atenção para as incongruências que podem ser ampliadas, mais do que para as críticas que lhes podem ser feitas. Mais do que simplesmente obedecer às normas, precisamos nos apropriar delas, assim como nos preparar para transformá-las em ocasião favorável. Eis a nossa "obrigação ética” (GROS, 2018). Para tanto, um primeiro passo é conhecê-las de perto. A publicação recente, em fevereiro de 2020, das novas Diretrizes Curriculares para a formação de professores nos serve aqui de oportunidade. Neste artigo, a prática e o estágio são mediadores fundamentais para se pensar as interseções entre museu e universidade, educação não formal e formal, educação em museus e licenciatura em artes.

\section{O lugar da prática na BNC-Formação}

Em 10 de fevereiro de 2020, o Ministério da Educação (MEC) publicou a Resolução $\mathrm{n}^{\circ} 2$, de 20 de dezembro de $2019,{ }^{2}$ que define as Diretrizes Curriculares Nacionais para a Formação Inicial de Professores para a Educação Básica e institui a Base

\footnotetext{
2 Por ter saído no Diário Oficial da União do dia 23 de dezembro de 2019 (na Seção 1, p. 115-119) com alguma incorreção, a Resolução precisou ser republicada, o que aconteceu no dia 10 de fevereiro de 2020.
} 


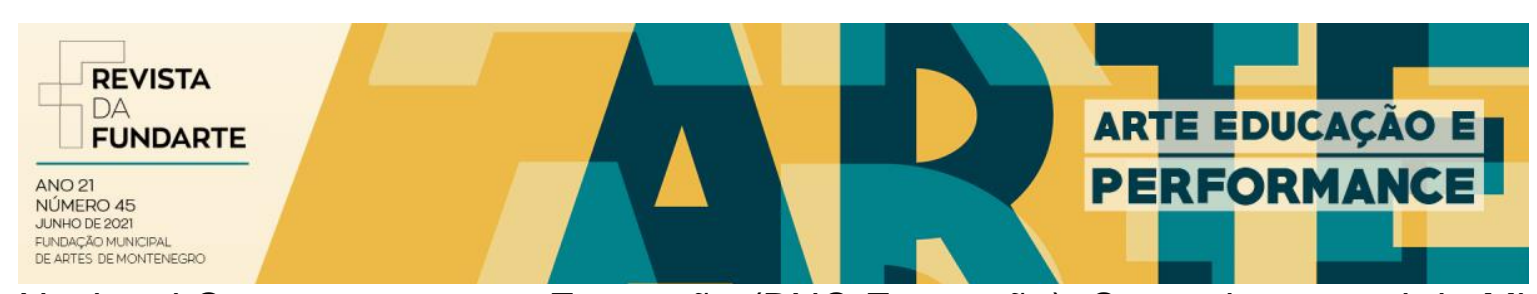

Nacional Comum para essa Formação (BNC-Formação). Segundo o portal do Ministério da Educação, uma das principais mudanças trazidas por essas Diretrizes consiste na "formação baseada em atividades práticas e presenciais" (MEC, 2020). A notícia destaca o terceiro parágrafo do Art. 15 da Resolução: "A prática deve estar presente em todo o percurso formativo do licenciando, com a participação de toda a equipe docente da instituição formadora". No mesmo Portal, uma notícia de 18 de dezembro de 2018 comentando a entrega da proposta da BNC-Formação pelo MEC ao Conselho Nacional de Educação (CNE) registra o que seria uma de suas premissas: "Em geral, os cursos [de formação dos docentes] contam com muita teoria e pouca prática, [...] além de estágios curriculares sem planejamento e sem vinculação com as escolas" (MEC, 2018b).

A proposta foi criticada por diferentes entidades e pesquisadores, entre outros motivos, por seu caráter "praticista" (ANFOPE; FORUMDIR, 2018; RODRIGUES et al., 2020; SILVA; BENTO, 2020). De fato, entre 2015 (ano em foi publicada a Resolução anterior) e 2019, sob a justificativa de alinhar a formação docente à Base Nacional Comum Curricular (BNCC), ${ }^{3}$ instituiu-se com muita ênfase a formação por competências e habilidades (ALBINO; SILVA, 2019; FARIAS, 2019). Certamente, a lista dos motivos para se criticar a BNC-Formação é maior: substituiu-se a valorização de múltiplas diversidades (étnico-racial, de gênero, sexual, religiosa etc.) pela ideia mais branda de "diversidade humana"; eliminou-se a gestão democrática do ensino público, além de todo um capítulo dedicado à valorização do magistério; substituiu-se a definição de planos de carreira e salário por uma menção genérica ao "fortalecimento dos saberes e práticas específicas de tal profissão" (Art. 60, II, da Resolução de 2019); dispensou-se o aprendizado da Língua Brasileira de Sinais (Libras). Mas voltemos à ênfase nas atividades práticas.

As críticas a uma visão praticista - no sentido de irrefletidamente pragmática ou que pensa a prática como lugar de aplicação técnico-instrumental da teoria - têm a sua razão, mas em que consiste a "mudança" trazida pela BNC-Formação? Se-

\footnotetext{
${ }^{3}$ Segundo Larissa Zancan Rodrigues et al. (2020, p. 9), se por um lado a BNC-Formação se apresenta como consequência da BNCC, por outro, ela também é um elemento fundamental para a existência e aplicação deste documento. A propósito, as autoras veem nesse alinhamento a causa de uma "tendência homogeneizadora" no campo das políticas de formação, avaliação, ingresso e carreira.
} 


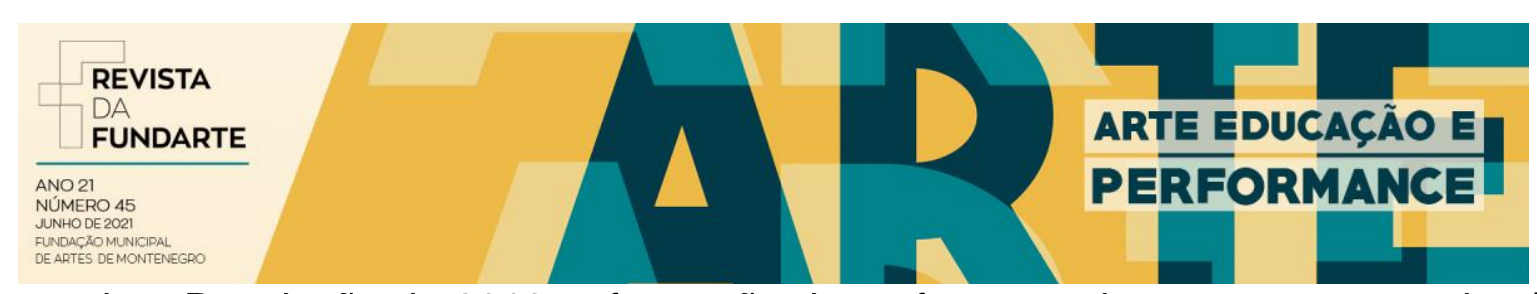

gundo a Resolução de 2019, a formação de professores deve ter uma carga horária mínima de 800 horas de prática pedagógica, dentro do chamado Grupo III da carga horária dos cursos de Licenciatura (Art. 11, III). Metade dessa carga horária deve ser destinada ao estágio supervisionado "em situação real de trabalho em escola" (Art. 11, III, a), enquanto a outra metade se destina à prática tanto dos conhecimentos educacionais, pedagógicos e/ou didáticos, que fazem parte do Grupo I (Art. 11, I), quanto dos conteúdos específicos das áreas de conhecimento, conforme a BNCC, que fazem parte do Grupo II (Art. 11, II). Segundo o que se propõe, essa ênfase na prática não estaria desvinculada de uma articulação entre teoria e prática (Art. 6으, V).

Mas a exigência dessas 800 horas aparece nas resoluções sobre o assunto desde pelo menos 1999 (cf. Tabela 1). Eis o que se lê no Art. $9^{\circ}$ da Resolução $\mathrm{CNE} / \mathrm{CP} \mathrm{n}^{\circ} 1$ daquele ano: "O curso normal superior e os demais cursos de licenciatura incluirão obrigatoriamente parte prática de formação, com duração mínima de 800 horas, oferecida ao longo dos estudos". Certamente, a Resolução de 2019 parece ampliar o espaço da prática dentro do que seriam os núcleos teóricos, com a inclusão no Grupo II de "estratégias que propiciem o contato prático com o mundo da educação e da escola" e da "articulação entre as atividades práticas realizadas na escola e na sala de aula com as que serão efetivadas durante o estágio supervisionado" (Art. 13, $\S 1^{\circ}, \mathrm{V}$ e VI). Desse modo, mesmo tendo eliminado a exigência de 200 horas de atividades teórico-práticas na Resolução de 2015, ela parece "ampliar" o espaço dessas atividades para uma parte das 1600 horas. Observe-se, no entanto, que metade daquelas 800 horas foi reservada, em direção oposta, à prática de componentes dos núcleos "teóricos". Em suma, todo esse trânsito parece mais reforçar a ideia de uma "articulação" entre teoria e prática, do que defender o praticismo.

\begin{tabular}{|l|l|l|l|}
\hline & $\begin{array}{l}\text { Resolução CNE/CP no } 2 \text { de } \\
2002\end{array}$ & $\begin{array}{l}\text { Resolução CNE/CP no } 2 \text { de } \\
2015\end{array}$ & $\begin{array}{l}\text { Resolução CNE/CP no } 2 \text { de } \\
2019\end{array}$ \\
\hline I & $\begin{array}{l}400 h \text { de prática como com- } \\
\text { ponente curricular, vivencia- } \\
\text { das ao longo do curso }\end{array}$ & $\begin{array}{l}400 \mathrm{~h} \text { de prática como com- } \\
\text { ponente curricular, distri- } \\
\text { buídas ao longo do proces- } \\
\text { so formativo }\end{array}$ & $\begin{array}{l}\text { 800h para a base comum } \\
\text { que compreende os conhe- } \\
\text { cimentos científicos, educa- } \\
\text { cionais e pedagógicos e } \\
\text { fundamentam a educação e } \\
\text { suas articulações com os } \\
\text { sistemas, as escolas e as } \\
\text { praticas educacionais }\end{array}$ \\
\hline
\end{tabular}




\begin{tabular}{|c|c|c|c|}
\hline \multicolumn{4}{|c|}{ 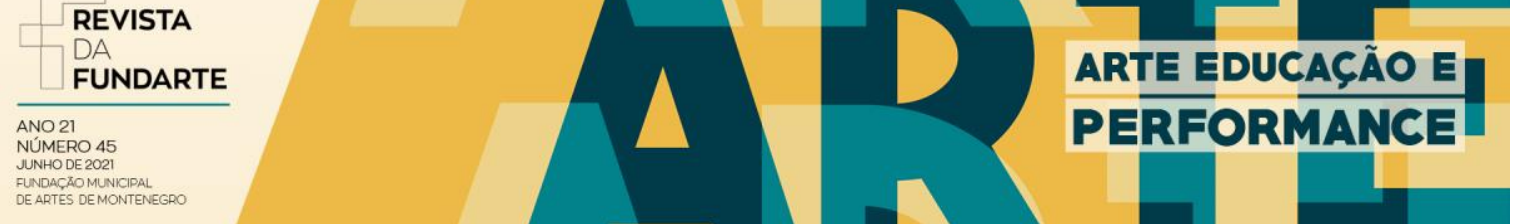 } \\
\hline II & $\begin{array}{l}\text { 400h de estágio curricular } \\
\text { supervisionado a partir do } \\
\text { início da segunda metade } \\
\text { do curso }{ }^{4}\end{array}$ & $\begin{array}{l}\text { 400h dedicadas ao estágio } \\
\text { supervisionado, na área de } \\
\text { formação e atuação na edu- } \\
\text { cação básica, contemplando } \\
\text { também outras áreas espe- } \\
\text { cificas, se for o caso [...] }\end{array}$ & $\begin{array}{l}\text { 1.600h para a aprendiza- } \\
\text { gem dos conteúdos especí- } \\
\text { ficos das áreas, componen- } \\
\text { tes, unidades temáticas e } \\
\text { objetos de conhecimento da } \\
\text { BNCC, e para o domínio } \\
\text { pedagógico desses conteú- } \\
\text { dos }\end{array}$ \\
\hline III & $\begin{array}{l}1800 \mathrm{~h} \text { de aulas para os } \\
\text { conteúdos curriculares de } \\
\text { natureza cientifico-cultural }\end{array}$ & $\begin{array}{l}\text { 2.200h dedicadas às ativi- } \\
\text { dades formativas estrutura- } \\
\text { das pelos núcleos definidos } \\
\text { nos incisos I e II do artigo } 12 \\
\text { desta Resolução [...] }\end{array}$ & $\begin{array}{l}\text { 800h de prática pedagógica } \\
\text { assim distribuídas: (a) } 400 \mathrm{~h} \\
\text { para o estágio supervisio- } \\
\text { nado, em situação real de } \\
\text { trabalho em escola, segun- } \\
\text { do o Projeto Pedagógico do } \\
\text { Curso (PPC) da instituição } \\
\text { formadora; e (b) } 400 \text { para } \\
\text { a prática dos componentes } \\
\text { curriculares dos Grupos I e } \\
\text { II, distribuídas ao longo do } \\
\text { curso, desde o seu início } \\
{[\ldots]}\end{array}$ \\
\hline IV & $\begin{array}{l}\text { 200h para outras formas de } \\
\text { atividades acadêmico- } \\
\text { científico-culturais }\end{array}$ & $\begin{array}{l}200 \mathrm{~h} \text { de atividades teórico- } \\
\text { práticas de aprofundamento } \\
\text { em áreas específicas de } \\
\text { interesse dos estudantes } \\
\text { [...], por meio da iniciação } \\
\text { científica, da iniciação à } \\
\text { docência, da extensão e da } \\
\text { monitoria, entre outras [...] }\end{array}$ & \\
\hline Total & $2800 \mathrm{~h}$ & $3200 \mathrm{~h}$ & $3200 \mathrm{~h}$ \\
\hline
\end{tabular}

Tabela 1: Distribuição da carga horária dos cursos de formação inicial de professores entre 2002 e 2019, segundo as diferentes Resoluções. Obs.: A tabela mantém a distribuição da carga horária em "grupos" (I, II, III e IV) tal como aparece em cada Resolução, de modo que não há, na tabela, uma correspondência entre os mesmos grupos das diferentes Resoluções. Por exemplo, o estágio curricular ou supervisionado aparece no grupo II das Resoluções de 2002 e 2015, mas consta no grupo III na Resolução de 2019.

De fato, a articulação ou associação entre teorias e práticas pedagógicas é tanto um fundamento quanto um princípio da Resolução de 2019 (Art. 5ํ, II e Art. 6º V). O documento preconiza uma "integração entre a teoria e a prática, tanto no que se refere aos conhecimentos pedagógicos e didáticos, quanto aos conhecimentos específicos da área do conhecimento ou do componente curricular a ser ministrado" (Art. 7ํㅡ, VII). Além disso, a Resolução reconhece que "a formação de professores

\footnotetext{
${ }^{4}$ Conforme a Resolução CNE/CP no 1 de 2002, Art. 13, § 3o, da qual a Resolução no 2 de 2002 é um complemento, "O estágio curricular supervisionado, definido por lei, a ser realizado em escola de educação básica, [...] deve ser desenvolvido a partir do início da segunda metade do curso e ser avaliado conjuntamente pela escola formadora e a escola campo de estágio".
}

HONORATO, Cayo. A educação não formal nas licenciaturas em artes visuais da perspectiva das políticas educacionais. Revista da FUNDARTE. Montenegro, p.01-19, ano 21, oㅡ 45, junho de 2021. Disponível em: http://.seer.fundarte.rs.gov.br/index.php/revistadafundarte/index> 30 de junho de 2021. 


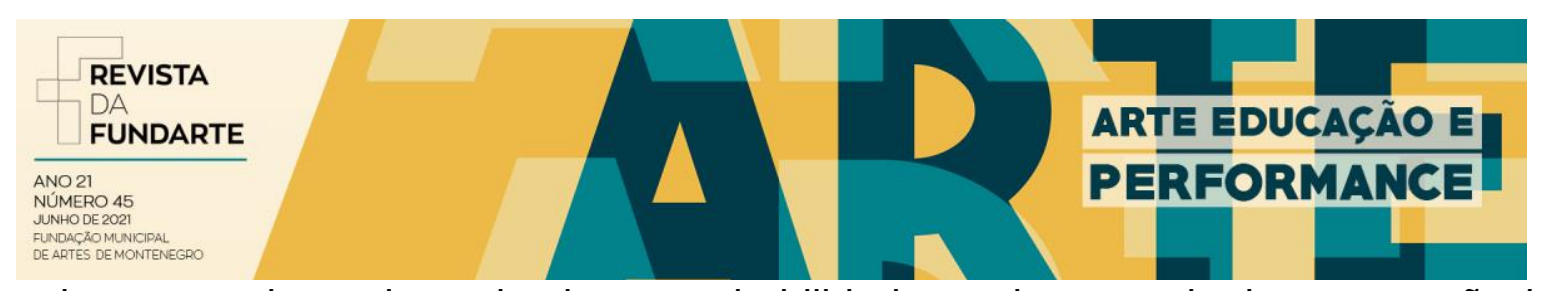

exige um conjunto de conhecimentos, habilidades, valores e atitudes, que estão inerentemente alicerçados na prática, a qual precisa ir muito além do momento de estágio obrigatório" (Art. 7º II, grifo meu). Ao mesmo tempo, postula a "centralidade da prática por meio de estágios que enfoquem o planejamento, a regência e a avaliação de aula" (Art. $7^{\circ}$, VIII). Desse modo, a "prática pedagógica" se configura como um lugar tanto de recepção quanto de produção de conhecimentos. Sua "centralidade" tem nos estágios um lugar mais evidente, embora não exclusivo. A prática opera como um elemento transversal do currículo.

Certamente, nada disso foi inventado pela BNC-Formação. A "unidade teoriaprática" é também um princípio da Resolução de 2015, fundado "no domínio dos conhecimentos científicos e didáticos, contemplando a indissociabilidade entre ensino, pesquisa e extensão" (Art. $\left.3^{\circ}, \S 5^{\circ}, \mathrm{V}\right)$. Esse trecho inclusive é repetido pela Resolução de 2019 (Art. 6ํ, V). Do mesmo modo, a de 2015 contempla a análise de dinâmicas didático-pedagógicas "articuladas à experiência dos professores das escolas de educação básica" (Art. $7^{\circ}, \mathrm{VII}$ ), assim como a "construção de conhecimentos pedagógicos e científicos, objetivando a reflexão sobre a própria prática" (Art. $8^{\circ}, \mathrm{XII}$, grifo meu). Isso aparece refletido na Resolução de 2019, na ideia de que a escola é o "lugar privilegiado da formação inicial do professor, da sua prática e da sua pesquisa" (Art. 8ํ, VII, grifo meu). Portanto, a ideia de que a Resolução de 2019 estaria mais centrada na prática do que a de 2015, só poderia prosperar maximizando alguns detalhes. Por exemplo, enquanto a de 2015 define que "deverá ser garantida, ao longo do processo, efetiva e concomitante relação entre teoria e prática" (Art. 13, $\S 3^{\circ}$, grifo meu), a de 2019 define que "a prática deve estar presente em todo o percurso formativo do licenciando" (Art. $15, \S 3^{\circ}$, grifo meu) - o que já constava na Resolução CNE/CP nº 1 de 2002 (Art. 12, § 2º).

Também seria oportuno confrontar e analisar diferenças entre as modalidades da relação entre teoria e prática, que podem inclusive ser internas a cada Resolução. Por exemplo, a alternância dos termos "articulação", "associação" e "integração" na Resolução de 2019, que a rigor têm sentidos diferentes um do outro, assinala certa ambiguidade no modo como ela concebe a relação entre teoria e prática. Além disso, enquanto o texto de 2015 registra que se trata de uma articulação expressa 


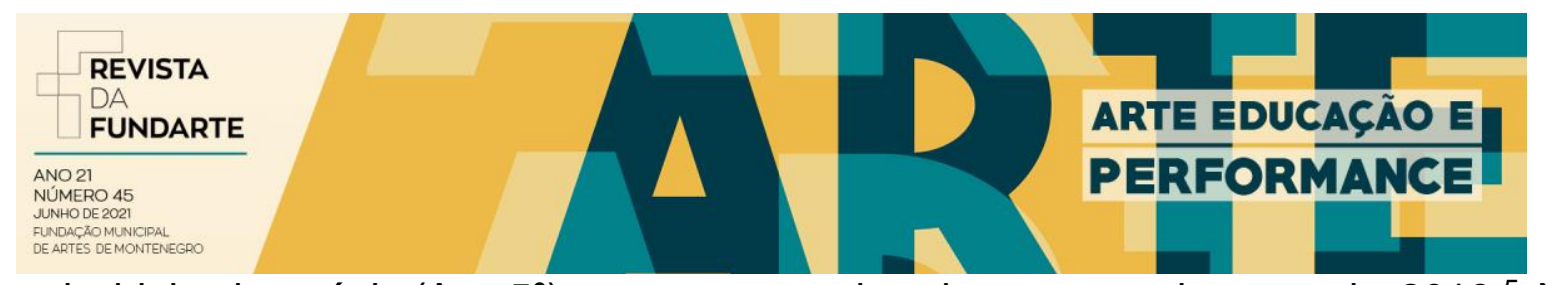

pela ideia de práxis (Art. 5º), essa perspectiva desaparece do texto de $2019 .{ }^{5} \mathrm{Na}$ verdade, a crítica a uma visão "praticista" critica a incorporação pela BNC-Formação da pedagogia das competências, que aparece na Resolução como se fosse um "paradigma dominante na educação no Brasil" - o que ignora as objeções feitas a essa pedagogia desde o fim dos anos 1990 (RODRIGUES et al., 2020, p. 26 ss). Também ela critica uma "tendência homogeneizadora" presente no alinhamento da formação docente à BNCC (cf. nota $\mathrm{n}^{\circ} 2$ ), que comprometeria a autonomia universitária assegurada pelo Art. 207 da Constituição Federal. Segundo as pesquisadoras Larissa Zancan Rodrigues, Beatriz Pereira e Adriana Mohr (2020, p. 29),

[...] é inédito, para a formação de professores, definir um currículo de formação centrado em competências e habilidades, as quais estão articuladas - e limitadas - com o que é pretendido na BNCC (...). Temos, dessa forma, uma agenda de formação, uma espécie de script fechado, que apresenta uma lógica homogeneizante e focada nos resultados [aferidos por testes padronizados], que não deixa margem para pensar a formação para a docência numa perspectiva larga e que considere a complexidade do ensinar, a diversidade dos contextos de trabalho, a pluralidade social dos discentes com os quais o professor lida e, sobretudo, para promover um desenvolvimento que valorize efetivamente esse profissional. (Farias, 2019, p. 163).

Dentre as várias razões enumeradas pelas pesquisadoras para contestar a proposta da BNC-Formação, está o modo como ela propõe a aproximação dos licenciandos aos contextos de trabalho. As autoras não questionam a necessidade de superarmos uma persistente dicotomia entre teoria e prática, mas observam que ela requer a valorização dos profissionais e instituições envolvidos, na forma de uma qualificação de suas condições de trabalho e espaço. Para elas, "É difícil qualificar esta aproximação sem planejamento e sem destinar parte da carga horária do docente da educação básica para coformação de futuros professores, por exemplo" (RODRIGUES et al., 2020, p. 25, grifo meu). De fato, o estágio costuma ser pensado como um elemento principal da relação entre universidade e escola. Na prática, ele é muito mais um elemento da universidade que geralmente pressupõe a disponibilidade da escola. Portanto, sem condições de trabalho, aumentar simplesmente o

\footnotetext{
${ }^{5}$ Mais do que um modo de articulação entre teoria e prática, o conceito de práxis tem geralmente uma dimensão política específica, que remonta quase sempre ao pensamento marxiano (cf. Vázquez, 1968; Löwy, 2012).
} 


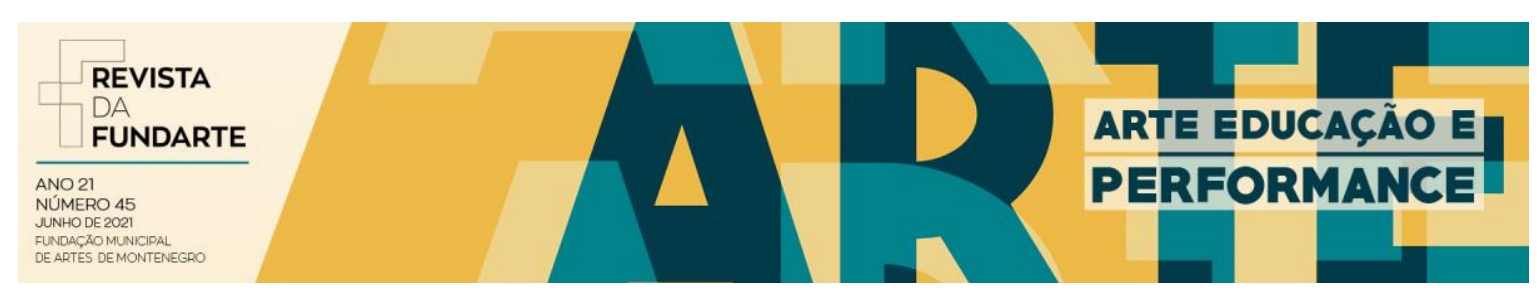

tempo dos licenciandos na escola pode não resultar em uma formação com mais qualidade.

\section{A vinculação do estágio à escola}

A crítica a uma visão praticista da política de formação docente pode, mais propriamente, ser reformulada nos termos de uma crítica dos impedimentos (políticos e conceituais) a um processo de constituição recíproca entre teoria e prática. Se por um lado a Resolução CNE/CP nº 2 de 2019 não garante as condições para o desdobramento desse processo, por outro, ela não determina que a prática seja um lugar de aplicação da teoria. Tampouco ela resulta num script absolutamente fechado, do qual não pudéssemos nos apropriar, antes da oportunidade de modificá-la. Assim, podemos também reformular a "centralidade da prática" nesse contexto, nos termos de uma relação transversal e desierarquizada entre essas duas instâncias. Do mesmo modo, podemos pensar que, mais do que somente a prática, é essa relação teoria/prática que tem nos estágios um lugar de destaque, particularmente, quando pensados e praticados como pesquisa (PIMENTA; LIMA, 2011, p. 44 ss). Além disso, experimenta-se nos estágios a relação não só entre universidade e escola, enquanto ambientes institucionais distintos, mas também entre formação e trabalho, com todas as implicações disso para a construção das identidades profissionais e os processos de compreensão e transformação da realidade.

Mas por que segundo as Diretrizes o estágio supervisionado deve ser cumprido exclusivamente na escola? Note-se que o próprio conceito de educação postulado pela LDBEN abrange processos informais e não formais (Lei 9.394/1996, Art. $\left.1^{\circ}\right)$. Certamente, não há razão para se questionar a vinculação dos estágios à escola. Os professores têm aí seu espaço de atuação primordial e, se estamos falando da formação de professores, é natural que a escola tenha prioridade. Ocorre que a vinculação do estágio exclusivamente à escola sacrifica justamente "a diversidade dos contextos de trabalho", mencionada por Rodrigues et al. (2020, p. 29), como parte da proposta de se "pensar a formação para a docência numa perspectiva larga" (FARIAS, 2019, p. 163). Neste ponto, as pesquisadoras se referem à diversidade socioeconômica entre as diferentes escolas, mais do que a diferentes locais de tra- 


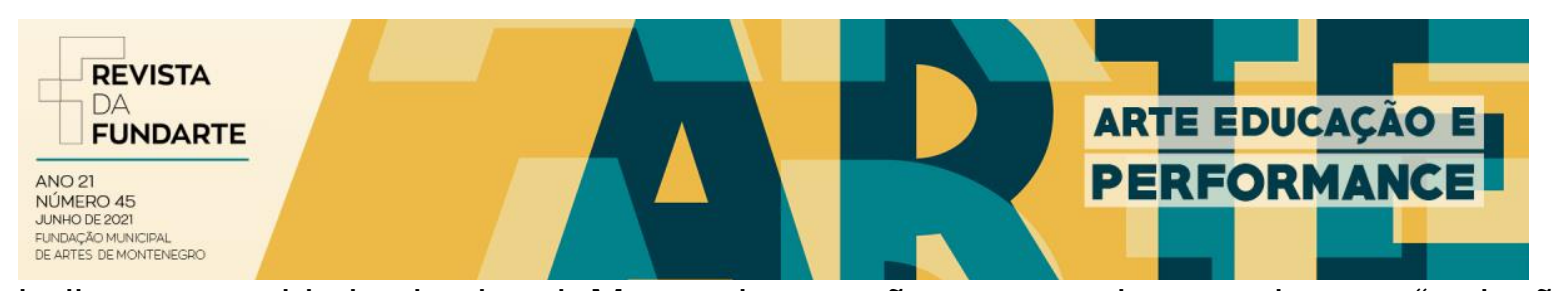

balho em sentido institucional. Mas a observação nos permite questionar a "redução" do licenciando a professor, em detrimento do educador social e do mediador cultural por exemplo. Afinal, a escola pode não ser a única "situação real de trabalho" para os licenciandos e, mesmo no caso dos que serão professores, há de se considerar a contribuição da educação não formal para sua formação.

Como vimos, a vinculação dos estágios à escola está prevista há bastante tempo. A Resolução de 2019 determina que o estágio ocorra "em situação real de trabalho em escola". A de 2015 estabelece que ele ocorra "na educação básica". A de 2002, que ele ocorra "em escola da educação básica". Desse modo, não parece haver espaço para o estágio no museu, terceiro setor, movimentos sociais etc. Por sua vez, as Diretrizes Curriculares do Curso de Graduação em Artes Visuais (Resolução CNE/CES no 1 , de 16 de janeiro de 2009) chegam a indicar, dentre as competências e habilidades que o profissional formado deverá possuir, a atuação "nos diferentes espaços culturais" (Art. $4^{\circ}, \mathrm{IV}$ ). Mas nesse documento, que parece ter o Bacharelado como referência, o estágio é um "componente curricular não obrigatório" (Art. $7^{\circ}$ ). Quando parte do currículo, suas atividades devem ser concebidas pelo Projeto Pedagógico do Curso (PPC), respeitando-se a regulamentação própria de cada IES (Art. 2 $2^{\circ}$, IX). Quanto às Licenciaturas, porém, essas Diretrizes determinam que os cursos "deverão observar as normas específicas relacionadas com essa modalidade de oferta" (Art. 11), que atualmente são definidas pela BNC-Formação.

A diferença de idade entre esses documentos (BNC-Formação e DCN-Artes Visuais) reflete a temporalidade própria da construção dos marcos legais. A propósito, tomemos como exemplo o atual PPC de Licenciatura em Artes Visuais da Universidade de Brasília. Ele foi discutido e concebido em 2010, entregue às instâncias superiores da universidade em 2011, mas só foi aprovado em 2018, tendo sua implementação iniciada em 2019. Em razão desse longo período de tramitação, o projeto precisou ser modificado algumas vezes, a fim de incorporar mudanças legais posteriores. O marco mais recente que ele considera é a Resolução CNE/CP n 2 de 2015. Buscando responder às possibilidades de atuação profissional dos egressos no contexto de Brasília, o projeto propôs uma alteração na nomenclatura do curso, na tentativa de abarcar múltiplas atuações: de "Licenciatura" para "Educação" em 


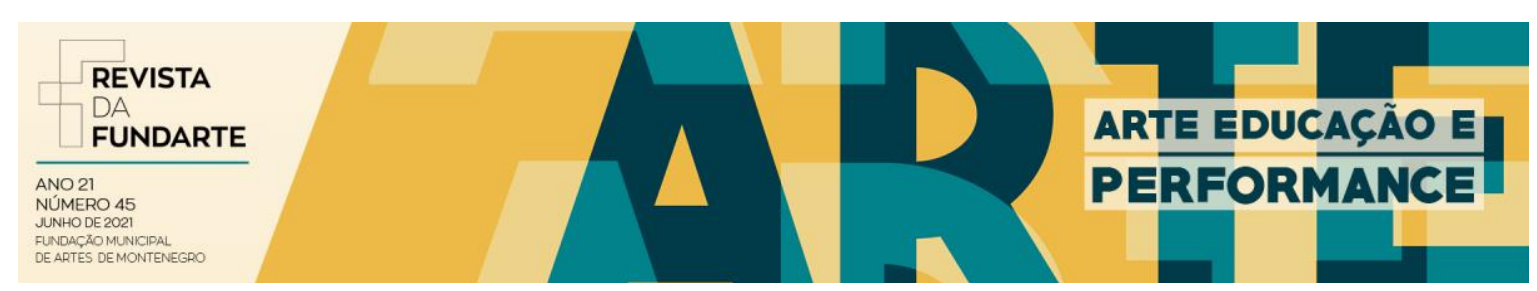

Artes Visuais - o que não foi aceito. Além disso, propôs a criação de duas ênfases:

(1) educação em espaços museais e (2) educação em ambientes virtuais de aprendizagem, sem prejuízo da formação de todos os egressos como professores da educação básica. ${ }^{6}$ Embora a oferta plena de cada uma dessas ênfases dependa de uma ampliação do quadro docente, mesmo que a primeira ênfase não seja plenamente oferecida, as disciplinas "Estágios Supervisionados em Artes Visuais - Espaços Museais", com 10 créditos (150 horas), e "Práticas de Ensino - Espaços Museais", com 4 créditos (60 horas), integram pela primeira vez o currículo obrigatório do curso. ${ }^{7}$

Por não garantir as 400 horas de estágio na escola, aquele PPC parece contrariar tanto a Resolução de 2019 quanto a de $2015 .{ }^{8}$ De fato, não fosse a prerrogativa da autonomia didático-científica das universidades, o propósito de atender demandas locais/regionais (cf. LDBEN, Art. 43, VI) não seria autorizado. Por outro lado, esse PPC não contraria a Lei do Estágio (Lei 11.788, de 25 de setembro de 2008). Essa lei define que o estágio é um "ato educativo" a ser desenvolvido "no ambiente de trabalho". Como se sabe, a possibilidade de usufruir dessa experiência não está reservada exclusivamente aos professores em formação, mas a todos os educandos que estejam frequentando o ensino regular em uma variedade de instituições de ensino, de forma nem sempre obrigatória. No caso do estágio obrigatório, a Lei exige que ele seja "definido como tal no projeto do curso" (Art. $2^{\circ}, \S 1^{\circ}$ ). De fato, segundo a LDBEN, "os sistemas de ensino" podem estabelecer "as normas de realização do estágio em sua jurisdição" (Art. 82). É claro, a Lei do Estágio também prevê a realização do "estágio escolar supervisionado", que entre outras condições deve ser acompanhado pelo "supervisor da parte concedente" (Art. $3^{\circ}$, $\S 1^{\circ}$ ). Mas em nenhum lugar ela restringe o estágio obrigatório à escola. Dentre as obrigações da parte concedente, há duas condições que caracterizam o local de estágio de forma suficiente: a primeira diz respeito à oferta de instalações que possam "proporcionar

\footnotetext{
${ }^{6}$ Diferentemente das habilitações, as ênfases permitiriam atualizações curriculares sem a necessidade de reformas estruturais, a fim de acompanhar mais de perto as mudanças de demanda para 0 curso.

7 Essa situação, naturalmente, difere de universidade para universidade. Um levantamento disso em âmbito nacional ainda precisa ser feito.

8 O PPC em questão garante 450 horas de estágio, distribuídas em três situações: "formação de professores", "espaços museais" e "ambientes virtuais de aprendizagem", com 150 horas cada. A princípio, somente a primeira seria desenvolvida na escola.
} 


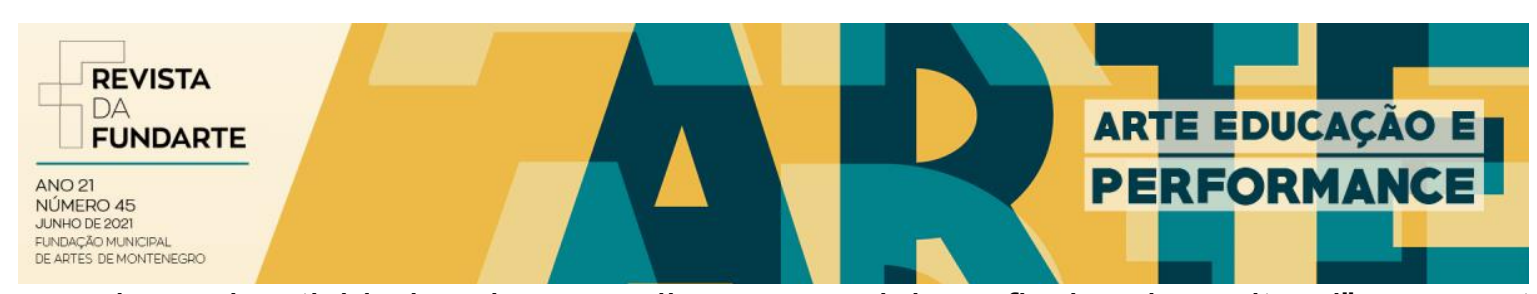

ao educando atividades de aprendizagem social, profissional e cultural"; enquanto a segunda se refere à exigência de que o supervisor tenha "formação ou experiência profissional na área de conhecimento desenvolvida no curso do estagiário" (Art. 9, II e III).

Resta-nos ainda problematizar a exclusividade da vinculação dos estágios à escola, a partir das próprias Diretrizes Curriculares para a formação docente. Dentre os princípios dessas diretrizes, segundo a Resolução CNE/CP n 2 de 2019, estão: "a compreensão dos docentes como agentes formadores de [...] cultura" e "a liberdade de aprender, ensinar, pesquisar e divulgar a cultura, o pensamento, a arte" (Art. 6, IX e X). Além disso, uma das "competências gerais docentes", segundo a BNC-Formação, implica "valorizar e incentivar [...] a participação em praticas diversificadas da produção artístico-cultural”. A propósito, essa competência praticamente repete uma das "competências gerais da educação básica", segundo a BNCC (MEC, 2018a, p. 9). Por sua vez, a BNCC reconhece os museus como espaços educativos de memória e cultura, que propiciam o exercício da crítica, apreciação e fruição das manifestações culturais, além de categoria do sistema das artes visuais (MEC, 2018a, p. 201, 355, 410 e 483). Por fim, uma das habilidades que o licenciando deve desenvolver, segundo a BNC-Formação, consiste justamente na utilização do conhecimento sobre a BNCC para "identificar como as dez competências da Base podem ser desenvolvidas na prática" (Habilidade 1.1.5). Logo, se o docente é um formador de cultura, se ele deve incentivar a participação em práticas de produção artístico-cultural, se os museus são espaços educativos de acesso a essas manifestações, e se essas competências devem ser desenvolvidas na prática, por que os estágios deveriam estar restritos à escola?

Certamente, a educação em museus não só faz parte da formação dos professores, podendo "arejar e ressignificar práticas de sala de aula" (NAKASHATO, 2009), como constitui um campo de atuação profissional independente - ou melhor, interdependente, mas em todo caso distinto - da educação formal escolar. Ainda com relação às brechas de que dispomos, a Resolução CNE/CES nº 07, de 18 de dezembro de 2018, relativa à curricularização da extensão, estabeleceu que "as atividades de extensão devem compor, no mínimo, 10\% (dez por cento) do total da 


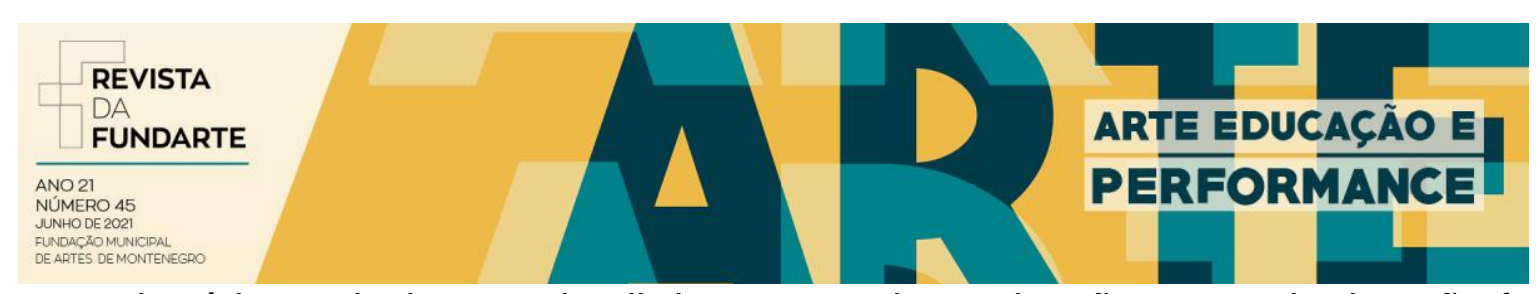

carga horária curricular estudantil dos cursos de graduação, as quais deverão fazer parte da matriz curricular dos cursos" (Art. $4^{\circ}$ ). Embora tenha como propósito "promover a interação transformadora entre as instituições de ensino superior e os outros setores da sociedade" (Art. $3^{\circ}$ ), sem portanto se comprometer em primeira instância com a formação profissional, mas sim com a formação cidadã do estudantes e a dimensão social do ensino e da pesquisa, as atividade de extensão podem ser caracterizadas como "prestação de serviços", limitadas em todo caso a programas institucionais ou de natureza governamental (Art. 8ำ, V e Art. 9º). Nesse sentido, tanto os museus universitários quanto os museus públicos, por meio de acordos de cooperação técnica, podem sediar projetos de extensão que contribuam com a formação de mediadores culturais.

Por último, podemos recorrer a um argumento de caráter histórico. A relação com a educação não formal tem para a história do ensino da arte um lugar que não pode ser negligenciado. Segundo Maria Heloisa Ferraz e Maria Fusari (2010, p. 18), o movimento Arte-Educação "organizou-se fora da educação escolar". Em meados dos anos 1980, Noêmia Varela (1986, p. 17) entende que "uma nova forma de capacitação do professor" envolveria "experiências realizadas no âmbito da educação formal e não-formal". Nesse momento, a educadora se refere ao Curso Intensivo de Arte e Educação, do qual foi diretora, e que foi, entre 1961 e 1973, o único curso de formação de professores de arte no país. O argumento é retomado por Guilherme Nakashato (2009, p. 30-42), para quem as contribuições resultantes do entrelaçamento destas duas modalidades constituem uma espécie de "débito epistemológico" da educação formal com a não-formal. O pesquisador destaca três momentos em que se deram esses "empréstimos": a Escolinha de Arte do Brasil e o Movimento Escolinhas de Arte, a partir de 1948; a sistematização da Proposta Triangular no Museu de Arte Contemporânea da USP, no fim dos anos 1980; e a mediação cultural, que vem se consolidando desde meados dos anos 1990.

\section{Algumas considerações}

Vimos que, por um lado, as resoluções a respeito da formação docente restringem a possibilidade do estágio obrigatório na educação não formal. Por outro 


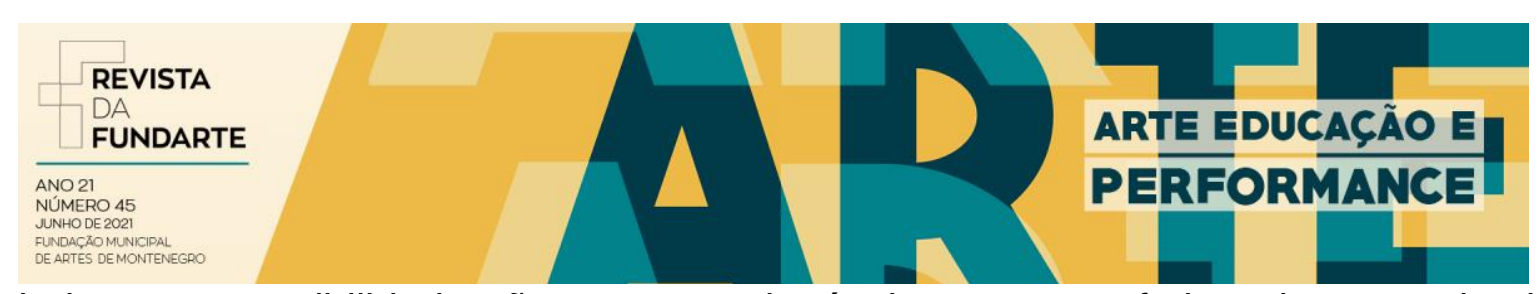

lado, essa possibilidade não encontra obstáculos para se efetivar do ponto de vista de outros marcos legais: da Constituição que assegura a autonomia didáticocientífica das universidades; da LDBEN que reconhece uma concepção abrangente de educação; da Lei do Estágio que não caracteriza o local de estágio em função do tipo de instituição. Mas são as incongruências internas às próprias Diretrizes Curriculares para a formação docente que mais chamam a atenção: como participar das manifestações culturais, sem poder atuar nos espaços que lhes são próprios? Tais incongruências, naturalmente, não chegam a varrer aquela restrição (do estágio à escola), mas podem amolecer sua consistência, ao sugerir que as diretrizes não escutam seus próprios princípios, aquilo que ela mesma pretende realizar.

Ao se voltarem para a educação formal, tais Diretrizes parecem simplesmente se ocupar daquilo que Ihes compete. Como vimos, porém, elas tendem a reforçar a ideia de que a escola detém o monopólio da educação, ou de que ser professor (da educação escolar) é a única destinação do licenciando. Não se trata aqui de insistir numa rivalidade entre essas instâncias (formal e não formal), mas de considerar as condições para uma colaboração efetiva entre elas. As Diretrizes atuais não só comprometem a possibilidade de que as escolas se construam como "pontos de intersecção de outras redes que reforçam seu sentido público" (GOHN, 2010, p. 14), por meio de colaborações com seu entorno geográfico, cultural e social. Elas também desreconhecem campos de pesquisa e atuação próprios, com larga trajetória no campo educacional: a educação não formal, a educação em museus e a mediação cultural.

Finalmente, alguns poderão dizer que, se a educação formal é caracterizada, entre outros elementos, por instituições regulamentadas, ambientes normatizados, conteúdos sistematizados, aprendizagens certificadas (GOHN, 2010, p. 17-21), não faria sentido as Diretrizes se ocuparem da educação não formal. Além disso, poderão dizer que a reivindicação de que as Diretrizes reconheçam a educação não formal terminaria por normatizá-la, por substituir a "livre escolha" pelo obrigatório. Em primeiro lugar, conforme a LDBEN, antes de uma imposição, a obrigatoriedade (da educação, do currículo e do estágio) está ligada a um direito. Portanto, é o direito de uma "perspectiva larga" para a docência o que se considera aqui. Em segundo, tais 


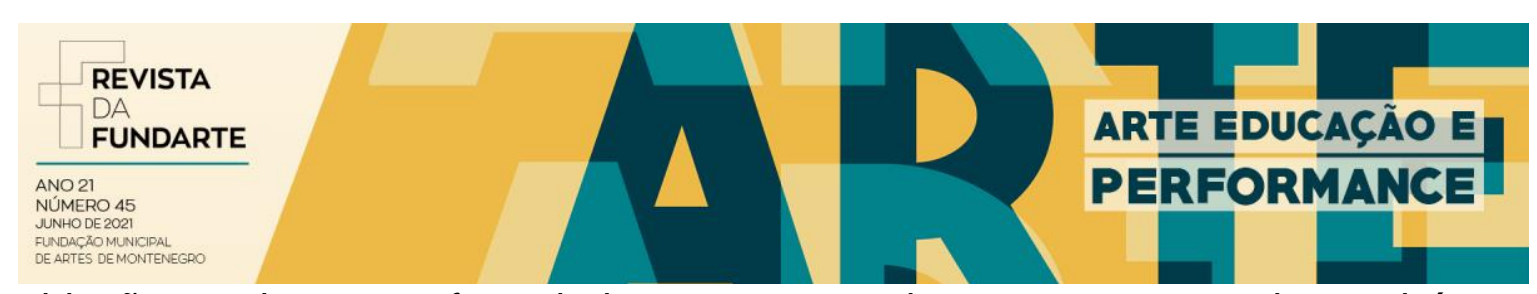

objeções podem ser reformuladas nos termos de uma pergunta pelos prejuízos que a educação formal teria ao se encastelar em si mesma. De fato, não se trata de normatizar a educação não formal, na direção de uma homogeneidade epistemológica, mas sim de buscar as condições para que uma heterogeneidade se desenvolva. Do mesmo modo, o "débito epistemológico" não é uma conta a ser paga, mas um espaço de interlocução a ser cultivado.

\section{Referências:}

ALBINO, Ângela C. A.; SILVA, Andréia F. da. BNCC e BNC da formação de professores: repensando a formação por competências. Revista Retratos da Escola, Brasília, v. $13, \quad$ n. 25, p. 137-153, jan./mai. 2019. Disponível em: <http//www.esforce.org.br>. Acesso em: 14 mai. 2020.

ALENCAR, Valéria P. de. O mediador cultural: Considerações sobre a formação e profissionalização de educadores de museus e exposições de Arte. 2008. Dissertação (Mestrado em Artes) - Instituto de Artes, UNESP, São Paulo, 108 p.

ANFOPE; FORUMDIR. Manifesto em defesa da formação de professores. Notícias da Anped, 17 dez. 2018. Disponível em: <http://www.anped.org.br/news/manifestoanfope-em-defesa-da-formacao-de-professores>. Acesso em: 14 mai. 2020.

BARBOSA, Ana Mae; COUTINHO, Rejane G. (org.). Arte/educação como mediação cultural e social. São Paulo: UNESP, 2009.

BRANDÃO, Carlos R. A educação como cultura. Campinas, SP: Mercado das Letras, 2002.

BRASIL. Lei n. 9.394, de 20 de dezembro de 1996. Estabelece as diretrizes e bases da educação nacional. Disponível em: <http://www.planalto.gov.br/ccivil_03/leis/l9394.htm>. Acesso em: 14 mai. 2020.

Lei 11.788, de 25 de setembro de 2008. Dispõe sobre o estágio de estudantes; [...] e dá outras providências. Disponível em: <http://www.planalto.gov.br/ccivil_03/_ato2007-2010/2008/lei/l11788.htm>. Acesso em: 14 mai. 2020.

CNE (Conselho Nacional de Educação). Resolução n. 1, de 30 de setembro de 1999. Dispõe sobre os Institutos Superiores de Educação [...]. Disponível em: $<$ http://portal.mec.gov.br/cne/arquivos/pdf/rcp001_99.pdf>. Acesso em: 14 mai. 2020.

Resolução n. 1, de 18 de fevereiro de 2002. Institui Diretrizes Curriculares Nacionais para a Formação de Professores da Educação Básica, em nível superior, 


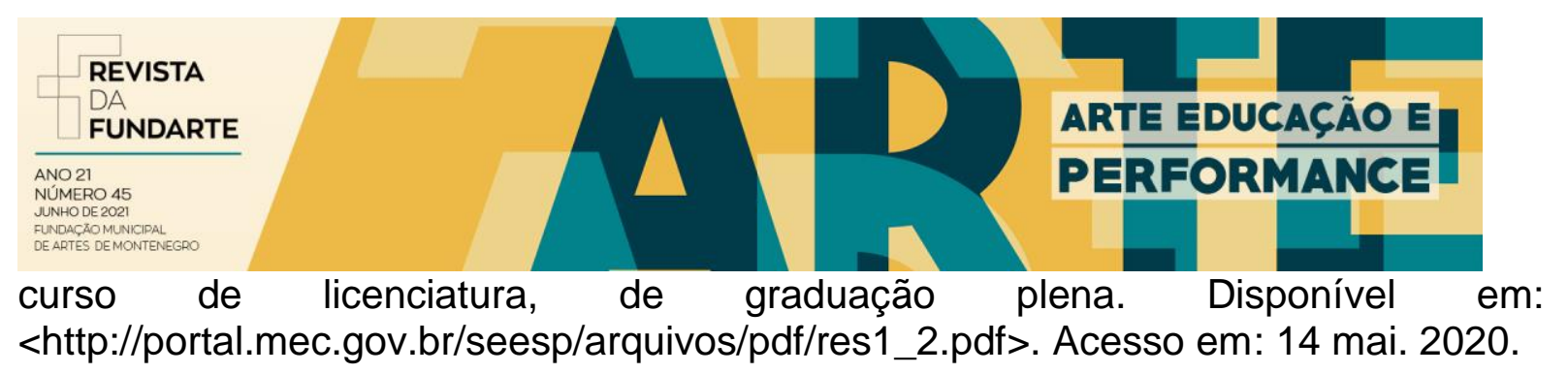

. Resolução n. 2, de 19 de fevereiro de 2002. Institui a duração e a carga horária dos cursos de licenciatura, de graduação plena, de formação de professores da Educação Básica em nível superior. Disponível em: $<$ http://portal.mec.gov.br/cne/arquivos/pdf/CP022002.pdf>. Acesso em: 14 mai. 2020.

. Resolução n. 1, de 16 de janeiro de 2009. Aprova as Diretrizes Curriculares Nacionais do Curso de Graduação em Artes Visuais e dá outras providências. Disponível em: <http://portal.mec.gov.br/cne/arquivos/pdf/2009/rces001_09.pdf>. Acesso em: 14 mai. 2020.

. Resolução n. 2, de 10 de julho de 2015. Define as Diretrizes Curriculares Nacionais para a formação inicial em nível superior (cursos de licenciatura, cursos de formação pedagógica para graduados e cursos de segunda licenciatura) e para a formação continuada. Disponível em: <http://portal.mec.gov.br/docman/agosto-2017pdf/70431-res-cne-cp-002-03072015-pdf/file>. Acesso em: 14 mai. 2020.

- Resolução n. 07, de 18 de dezembro de 2018. Estabelece as Diretrizes para a Extensão na Educação Superior Brasileira [...] e dá outras providências. Disponível em:

<http://portal.mec.gov.br/index.php?option=com_docman\&view=download\&alias=10 4251-rces007-18\&category_slug=dezembro-2018-pdf\&ltemid=30192>. Acesso em: 14 mai. 2020.

. Resolução n. 2, de 20 de dezembro de 2019. Define as Diretrizes Curriculares Nacionais para a Formação Inicial de Professores para a Educação Básica e institui a Base Nacional Comum para a Formação Inicial de Professores da Educação Básica (BNC-Formação). Disponível em: <http://portal.mec.gov.br/docman/dezembro2019-pdf/135951-rcp002-19/file>. Accessor em: 14 mai. 2020.

FALK, John H.; DIERKING, Lynn D. Lessons without limit: how free-choice learning is transforming education. Walnut Creek, CA: AltaMira Press, 2002.

FARIAS, Isabel M. S. de. O discurso curricular da proposta para BNC da formação de professores da educação básica. Revista Retratos da Escola, Brasília, v. 13, n. 25, p. 155-168, jan./mai. 2019. Disponível em: <http//www.esforce.org.br>. Acesso em: 14 mai. 2020.

FERRAZ, Maria H. C. de T.; FUSARI, Maria F. de Rezende e. Arte na educação escolar. 4. ed. São Paulo: Cortez, 2010.

GOHN, Maria da G. Educação não formal e o educador social: atuação no desenvolvimento de projetos sociais. São Paulo: Cortez, 2010.

. Educação não formal no campo das artes. São Paulo: Cortez, 2015.

HONORATO, Cayo. A educação não formal nas licenciaturas em artes visuais da perspectiva das políticas educacionais. Revista da FUNDARTE. Montenegro, p.01-19, ano 21, № 45, junho de 2021. Disponível em: http://.seer.fundarte.rs.gov.br/index.php/revistadafundarte/index> 30 de junho de 2021. 


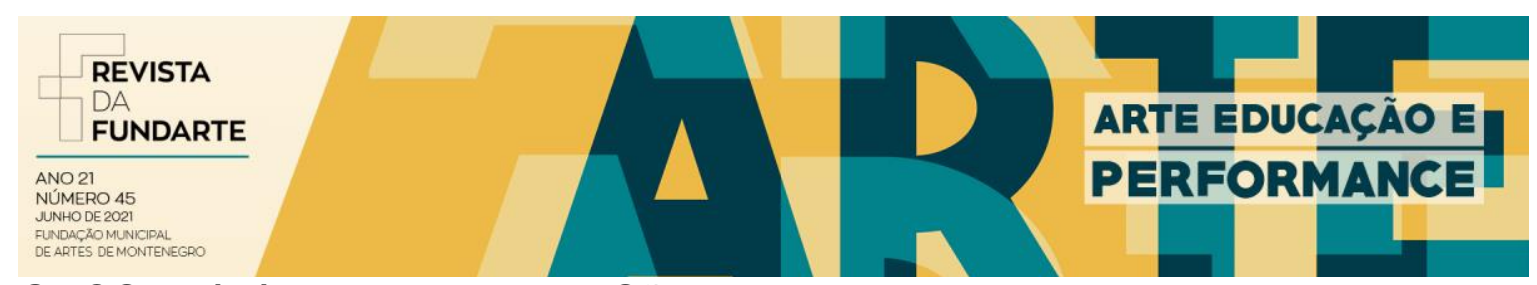

GROS, Frédéric. Desobedecer. São Paulo: Ubu Editora, 2018.

JACOBI, Daniel (ed.). Culture et éducation non formelle. Québec: Presses de l'Université du Québec, 2018.

LÖWY, Michael. A teoria da revolução no jovem Marx; tradução de Anderson Gonçalves. São Paulo: Boitempo, 2012.

MAGALHÃES, Ana Del T. V. Ensino de arte: perspectivas com base na prática de ensino. In: BARBOSA, Ana Mae (org.). Inquietações e mudanças no ensino da arte. São Paulo: Cortez, 2002, p. 161-74.

MARANDINO, Martha. Faz sentido ainda propor a separação entre os termos educação formal, não formal e informal? Ciência \& Educação, Bauru, v. 23, n. 4, p. 811816, out./dez. 2017. Disponível em: <https://doi.org/10.1590/1516731320170030001>. Acesso em: 14 mai. 2020.

MEUNIER, Anik. L'éducation dans les musées: une forme d'éducation non formelle. In: JACOBI, Daniel (ed.). Culture et éducation non formelle. Québec: Presses de l'Université du Québec, 2018, p. 15-32.

MEC (Ministério Da Educação). Base Nacional Comum Curricular: educação é a base. Brasília, [S.n.], 2018a, 600 p.

Proposta de novas normas para a formação do professor avança. Portal do Ministério da Educação. 18 dez. 2018 [2018b]. Disponível em: <http://portal.mec.gov.br/component/tags/tag/50631>. Acesso em: 14 mai. 2020.

Resolução define diretrizes para formação de professores. Portal do Ministério da Educação. 11 fev. 2020. Disponível em: <http://portal.mec.gov.br/busca-geral/12noticias/acoes-programas-e-projetos-637152388/85481-resolucao-define-diretrizespara-formacao-de-professores>. Acesso em: 14 mai. 2020.

MOURA, Lídice R. de. Arte e Educação: uma experiência de formação de educadores mediadores. 2007. Dissertação (Mestrado em Artes) - Instituto de Artes, UNESP, São Paulo, 185 p.

NAKASHATO, Guilherme. A educação não-formal como campo de estágio: contribuições na formação inicial do arte/educador. 2009. Dissertação (Mestrado em Artes) - Instituto de Artes, UNESP, São Paulo, 121 p.

PIMENTA, Selma G.; LIMA, Maria S. L. Estágio e docência. 6. ed. São Paulo: Cortez, 2011.

RODRIGUES, Larissa Z.; PEREIRA, Beatriz; MOHR, Adriana. O Documento "Proposta para Base Nacional Comum da Formação de Professores da Educação Bási- 


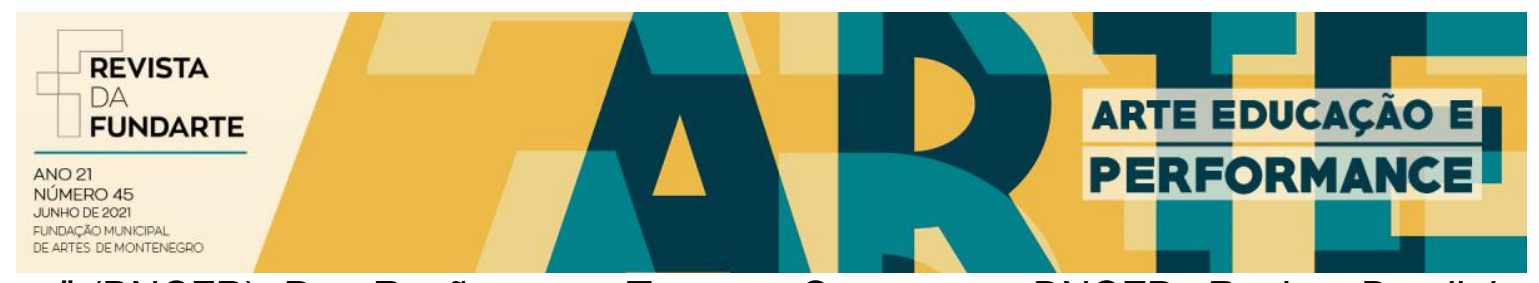

ca" (BNCFP): Dez Razões para Temer e Contestar a BNCFP. Revista Brasileira de Pesquisa em Educação em Ciências, v. 20, p. 1-39, jan./dez. 2020. Disponível em: <https://doi.org/10.28976/1984-2686rbpec2020u139>. Acesso em: 14 mai. 2020.

SILVA, Edileuza F.; BENTO, André. Concepções e discursos sobre a docência: tensões, embates e perspectivas. Ensino em Revista, v. 27, n. 1, p. 15-39, jan./abr. 2020. Disponível em: <http://dx.doi.org/10.14393/ER-v27n1a2020-1>. Acesso em: 14 mai. 2020.

VARELA, Noemia de A. A formação do arte-educador no Brasil. In: BARBOSA, Ana Mae (org.). História da arte-educação. São Paulo: Max Limonad, 1986, p. 11-27.

VÁZQUEZ, Adolfo S. Filosofia da praxis; tradução de Luiz Fernando Cardoso. Rio de Janeiro: Paz \& Terra, 1968. 